\title{
Human Milk From Atopic Mothers Has Lower Levels of Short Chain Fatty Acids
}

\section{OPEN ACCESS}

Edited by:

Willem Van Eden,

Utrecht University, Netherlands

Reviewed by:

Hauke Smidt,

Wageningen University and Research, Netherlands

Linette Willemsen,

Utrecht University, Netherlands

*Correspondence:

Anita L. Kozyrskyj

kozyrsky@ualberta.ca

tThese authors share senior authorship

Specialty section:

This article was submitted to Nutritional Immunology, a section of the journal

Frontiers in Immunology

Received: 14 January 2020 Accepted: 03 June 2020 Published: 21 July 2020

Citation:

Stinson LF, Gay MCL, Koleva PT,

Eggesbø M, Johnson CC Wegienka G, du Toit E, Shimojo N, Munblit D, Campbell DE, Prescott SL,

Geddes DT and Kozyrskyj AL (2020)

Human Milk From Atopic Mothers Has

Lower Levels of Short Chain Fatty

Acids. Front. Immunol. 11:1427.

doi: 10.3389/fimmu.2020.01427

\author{
Lisa F. Stinson ${ }^{1,2}$, Melvin C. L. Gay ${ }^{1,2}$, Petya T. Koleva ${ }^{2,3}$, Merete Eggesbo ${ }^{2,4}$, \\ Christine C. Johnson ${ }^{2,5}$, Ganesa Wegienka ${ }^{2,5}$, Elloise du Toit ${ }^{2,6}$, Naoki Shimojo ${ }^{2,7}$, \\ Daniel Munblit ${ }^{2,8,9}$, Dianne E. Campbell ${ }^{2,10}$, Susan L. Prescott ${ }^{2,11}$, Donna T. Geddes ${ }^{1,2 t}$ and \\ Anita L. Kozyrskyj ${ }^{2,3 * t}$
}

\begin{abstract}
${ }^{1}$ School of Molecular Sciences, University of Western Australia, Perth, WA, Australia, ${ }^{2}$ inVIVO Planetary Health of the Worldwide Universities Network (WUN), West New York, NJ, United States, ${ }^{3}$ Department of Pediatrics, University of Alberta, Edmonton, AB, Canada, ${ }^{4}$ Department of Environmental Exposure and Epidemiology, Norwegian Institute of Public Health, Oslo, Norway, ${ }^{5}$ Department of Public Health Sciences, Henry Ford Hospital, Detroit, MI, United States, ${ }^{6}$ Division of Medical Microbiology, University of Cape Town, Cape Town, South Africa, ' Department of Pediatrics, Chiba University, Chiba, Japan, ${ }^{8}$ Department of Paediatrics and Paediatric Infectious Diseases, Institute of Child Health, Sechenov First Moscow State Medical University (Sechenov University), Moscow, Russia, ${ }^{9}$ Inflammation, Repair and Development Section, National Heart \& Lung Institute, Imperial College London, London, United Kingdom, ${ }^{10}$ Department of Allergy and Immunology, Children's Hospital at Westmead, University of Sydney, Sydney, NSW, Australia, " The ORIGINS Project, Telethon Kids Institute, University of Western Australia, Perth, WA, Australia
\end{abstract}

Short chain fatty acids (SFCAs) are microbial metabolites produced in the gut upon fermentation of dietary fiber. These metabolites interact with the host immune system and can elicit epigenetic effects. There is evidence to suggest that SCFAs may play a role in the developmental programming of immune disorders and obesity, though evidence in humans remains sparse. Here we have quantified human milk (HM) SCFA levels in an international cohort of atopic and non-atopic mothers $(n=109)$. Our results demonstrate that human milk contains detectable levels of the SCFAs acetate, butyrate, and formate. Samples from atopic mothers had significantly lower concentrations of acetate and butyrate than those of non-atopic mothers. HM SCFA levels in atopic and non-atopic women also varied based on maternal country of residence (Australia, Japan, Norway, South Africa, USA). Reduced exposure to HM SCFA in early life may program atopy or overweight risk in breastfed infants.

Keywords: human milk, short chain fatty acids, atopy, allergy, international cohort, breast milk

\section{INTRODUCTION}

Human milk (HM) confers numerous benefits to the developing infant, an effect attributed to its many bioactive metabolites. The evidence for some of the long-term health benefits of HM is inconclusive (1). Regarding the prevention of atopic diseases through breastfeeding, this varies across countries and in particular, according to the atopic phenotype of the mother (2). While genetics and epigenetics play a role in the inheritance of atopic disease $(3,4)$, the role of HM metabolites remains underexplored in this field. Still in its infancy, the study of the HM metabolome has proven valuable in identifying variability by maternal phenotype, diet, and disease state $(5,6)$. Short chain fatty acids (SCFAs) are key metabolites of microbial fermentation of fiber that have links with host health. Early-life exposure to SCFAs has been shown to protect against atopy (7). 
When administered to pregnant mice, the SCFA acetate has prevented offspring from developing atopic airway inflammation (8). These findings are corroborated by human data of associations between high maternal serum acetate levels during pregnancy and decreased risk of respiratory symptoms in young infants (8). Similarly, propionate has been shown to protect against allergic airway disease in mice via its effects on dendritic cell biology (9), while butyrate induces the differentiation of colonic regulatory $\mathrm{T}$ cells (10). Further, murine studies have demonstrated that prebiotic fiber supplementation during pregnancy or lactation reduces risk of atopy in offspring $(11,12)$. Similar trials are currently underway in humans [SYMBA (13) and PREGRALL (14)]. Recently, Lee-Sarwar et al. reported higher fecal acetate levels (relative to total SCFA) in pregnant women of children less likely to develop atopic disease (15).

SCFAs (formate, acetate, propionate, butyrate, and valerate) are intermediate and end products of dietary carbohydrate fermentation by gut bacteria (7). These microbial metabolites are concentrated in the colon and some are distributed systemically after absorption $(8,9,16)$. Through their interaction with G-protein-coupled receptors and their inhibition of histone deacetylases, SCFAs are able to elicit a broad range of biological effects, including promotion of regulatory $\mathrm{T}$ cell responses and tolerance, mucus secretion and epithelial barrier integrity in the gut, and synthesis of bone marrow dendritic cell precursors $(9,17,18)$. A broad range of bacteria are also present in HM (19). HM SCFAs are likely produced by the maternal gut microbiota and distributed to the mammary gland via the circulation. They may also be produced by the resident HM microbiota; however, evidence for this possibility is currently lacking. To date, there has been limited investigation into HM SCFA profiles. Smilowitz et al. were the first to document the presence of acetate and butyrate in HM samples collected 90 days postpartum, finding that these SCFAs were highly variable among women (20). In HM samples from a single woman, acetate, butyrate and formate were detected as early as 24 days postpartum (21). All three of these SCFAs were identified by nuclear magnetic resonance (NMR) at 1-2 months postpartum in a larger study of women (22). Butyrate has also been documented in studies of HM fat or fatty acids $(23,24)$. Meng et al. reported the presence of acetate and butyrate in HM from women with and without irritable bowel disease, finding higher acetate levels in women treated with aminosalicylates (25). Finally, Gómez-Gallego et al. performed NMR metabolic profiling of 79 HM samples from 4 international cohorts. They identified acetate, butyrate, and formate in these samples and reported differences in acetate and formate levels between countries (26).

Total SCFA levels are elevated in the stool of lactating women at 1 month postpartum compared to non-pregnant women (27), implicating their importance to the nursing infant. HM SCFAs have been shown experimentally to prevent atopic disease, but breastfeeding by atopic mothers does not protect against atopy to the same extent as breastfeeding by non-atopic mothers (2). This discrepancy may be a function of reduced levels of SCFAs in $\mathrm{HM}$ among atopic mothers, though this has not been tested. Herein, we profiled SCFA levels in HM samples from atopic and non-atopic mothers from six international sites, including two countries with high rates of atopic disease. We hypothesized that atopic women would exhibit reduced levels of HM SCFAs.

\section{METHODOLOGY}

\section{Study Design}

In this descriptive study, 109 HM samples from 6 cohort studies from different countries were analyzed (5). The cohorts were from Perth, Australia ( $n=29$ from 2 cohorts); Chiba, Japan $(n=12)$; Detroit, USA $(n=18)$; Oslo, Norway $(n=40)$; Cape Town, South Africa $(n=10)$. These cohorts were sampled across countries to identify women with and without atopic disease. Whenever possible, samples were obtained from women who delivered vaginally and did not receive antibiotics while breastfeeding. To reduce the impact of maternal diet or genetics, an effort was made to obtain samples from women of the same ethnicity within a country. Research ethics approval was obtained from the local ethics committees of participating institutions: Human Research Ethics Committee of The University of Western Australia, Human Research Ethics Committee of the Princess Margaret Hospital, Committee on Human Research of Chiba University, Institutional Review Board at Henry Ford Health System, Norwegian Regional Committees for Medical and Health Research Ethics, and University of Cape Town Human Research Ethical Committee.

\section{Maternal Atopic Status}

Maternal atopic status was defined according to maternal report of having asthma, eczema or atopic dermatitis, or a pet, environmental or food allergy (Norwegian, South African women), or atopic sensitization on the basis of at least one blood allergen-specific IgE level $\geq 0.35 \mathrm{kU} / \mathrm{L}$ (US women) to house dust mite, dog, cat, Timothy grass, ragweed, Alternaria alternata, egg, or German cockroach, or at least one blood allergen-specific IgE level $\geq 0.7 \mathrm{kU} / \mathrm{L}$ (Japanese women) to house dust mite, cat or Japanese cedar, or at least one positive skin prick test (Australian women) to house dust mite, dog, cat, Timothy grass, Japanese cedar where applicable, ragweed, Alternaria alternata, egg, or German cockroach. Australian and Japanese atopic women also had a physician-diagnosed history of asthma, eczema or atopic dermatitis concurrent with atopic sensitization.

\section{Human Milk Sample Collection}

HM samples were collected 1 month after birth, a time point at which the composition of human milk is thought to stabilize (28). Participants were given written and oral instructions to standardize self-collection of samples. Prior to collection, nipples and mammary areola were cleaned with soap and sterile water, and for the samples from South Africa, additional cleaning was performed with chlorhexidine to reduce contamination by skin microbes. Human milk samples were expressed manually or with an electric breast pump into a sterile tube. Australian samples from non-atopic women (2015) and Norwegian samples (2002) were stored at $-20^{\circ} \mathrm{C}$, Australian samples from atopic women (2002) and samples from US women (2003) were stored at $-80^{\circ} \mathrm{C}$. The samples from Japanese women (2010) were initially stored at $-80^{\circ} \mathrm{C}$ before being moved to $-30^{\circ} \mathrm{C}$. Samples were 
shipped on dry ice to The Metabolomics Innovation Center, Edmonton, Canada for processing in 2015.

\section{NMR Analysis}

Milk metabolite levels were determined by NMR because of its high reproducibility and coverage of a large range of metabolites. Samples were analyzed as previously reported by Gay et al. (5). Briefly, samples were thawed on ice, mixed thoroughly, and then filtered to remove residual lipids and proteins using a 3$\mathrm{kDa}$ cutoff spin filter at $10,000 \times g$ for $15 \mathrm{~min}$ at $4^{\circ} \mathrm{C}$. Three hundred fifty microliter of filtrate was transferred to a clean tube, and $70 \mu \mathrm{L}$ of $\mathrm{D}_{2} \mathrm{O}$ and $60 \mu \mathrm{L}$ of standard buffer solution (585 $\mathrm{mM} \mathrm{NaHPO}_{4}$ (pH 7.0), $11.667 \mathrm{mM}$ disodium-2,2-dimethyl2-silapentane-5-sulfonate (DSS), and $0.47 \% \mathrm{NaN}_{3}$ in $\mathrm{H}_{2} \mathrm{O}$ ) were added. Samples were then transferred to regular NMR tubes for subsequent NMR spectral analysis. All 1H-NMR spectra were collected on a Varian $500 \mathrm{MHz}$ Inova spectrometer equipped with a 5-mm HCN Z-gradient pulsed-field gradient cryogenic probe. $1 \mathrm{H}-\mathrm{NMR}$ spectra were acquired at $25^{\circ} \mathrm{C}$ using the first transient of the Varian tnnoesy pulse sequence (chosen for its high degree of selective water suppression and quantitative accuracy of resonances around the solvent). Water suppression pulses were calibrated to achieve a bandwidth of $80 \mathrm{G}$. Spectra were collected with 128 transient and 8 steady-state scans using a 4-s acquisition time (48,000 complex points) and a 1-s recycle delay. Quality control (QC) mixtures consisting of 4 metabolites at $1 \mathrm{mM}$ were analyzed for every 20 to 25 samples, and a relative standard deviation of $<2 \%$ was observed. Prior to spectral analysis, all free induction decays were zerofilled to 64,000 data points and line broadened to $0.5 \mathrm{~Hz}$. The methyl singlet produced by a known quantity of DSS was used as an internal standard for chemical shift referencing (set to $0 \mathrm{ppm}$ ) and for quantification. All $1 \mathrm{H}-\mathrm{NMR}$ spectra were processed and analyzed using the Chenomx NMR Suite Professional software package version 8.1. Typically, 90\% of visible peaks were assigned to a compound, and more than $90 \%$ of the spectral area could be routinely fit using the Chenomx spectral analysis software. Most of the visible peaks were annotated with a compound name and expressed as $\mu \mathrm{mol} / \mathrm{L}$. The limit of detection for these compound was 5$6 \mu \mathrm{mol} / \mathrm{L}$.

\section{Statistical Analysis}

Statistical analyses were carried out using $\mathrm{R}$ studio 1.1.414 (Rstudio Inc., Boston, MA, USA) with package nlme for linear mixed models to test statistically significant differences between HM metabolites by atopic status within each country and by country within atopic status. The Tukey-Kramer test was used to adjust for multiple comparisons. Differences were considered to be statistically significant if $p<0.05$. Partial Least Squared Discriminant Analysis (PLS-DA) plots were created using an Excel add-in Multibase 2015 package (Numerical Dynamics, Japan) to maximize the separation of HM clusters by maternal atopic status. Correlations between SCFAs were determined using Spearman's rank correlation.

\section{RESULTS}

Of the 109 participating women, $43 \%$ were classified as atopic (Table 1). There was generally an even distribution of atopic/non-atopic mothers between the cohorts, except for South Africa, where only non-atopic women were sampled. Overall, $69 \%$ of participants were Caucasian. The majority of South African women were of mixed race, $39 \%$ of the US cohort were African American, and most of the Australian and Norwegian cohorts were of Caucasian ancestry. Cohorts were comparable with respect to maternal age, parity and pre-pregnancy BMI; Japanese women had the lowest BMI, whereas Australian women were the oldest and had the lowest parity. All but one woman had delivered vaginally. Only nine women reported taking antibiotics and use was during early pregnancy or delivery.

Full metabolomic data from this cohort have previously been reported (5). In brief, HM samples from atopic and non-atopic mothers clustered separately (Supplementary Figure 1). For the purposes of this study, we have focused on the SCFAs in HM, which have not been previously reported in this cohort.

\section{Human Milk Contains Short Chain Fatty Acids}

All samples contained detectable levels of acetate, butyrate, and formate (Table 2). Propionate and valerate were not detected in any of the samples. Butyrate was the most abundant SCFA in these samples (median level of $95.6 \mu \mathrm{mol} / \mathrm{L}$ ), followed by acetate (median level of $46.8 \mu \mathrm{mol} / \mathrm{L}$ ), and formate (median level of 43.7 $\mu \mathrm{mol} / \mathrm{L}$ ). There were statistically significant positive correlations between acetate and butyrate $\left(\right.$ rho $\left.=0.55, p=6.66 \times 10^{-10}\right)$ and acetate and formate levels (rho $=0.33, p=0.0006$ ). The SCFA intermediates pyruvate, lactate, and succinate were also detected (Supplementary Table 1).

\section{Human Milk Short Chain Fatty Acids Differ Geographically and by Maternal Atopic Status}

HM from atopic women had significantly lower levels of the SCFAs acetate $(p=0.02)$ and butyrate $(p=0.001)$ than that of non-atopic women (Figure 1). Median levels of these SCFAs in atopic women were approximately half that of their non-atopic counterparts (57\% lower for acetate, $62 \%$ lower for butyrate). Only for Australian women, of whom 100\% were Caucasian, were acetate and butyrate levels significantly lower in those with vs. those without atopy ( $p=0.009$ and $p=0.002$, respectively). Acetate levels were lower in atopic vs. non-atopic Norwegian (85\% Caucasian, $p=0.009$ ). The reduction in HM acetate levels with atopy in Japanese women $(100 \%$ Asian) did not reach statistical significance $(p=0.2)$. Among women from the US (61\% Caucasian), HM acetate levels were higher with atopic than non-atopic disease $(p=0.02)$. This difference was driven by samples from atopic Black women as when the comparison was restricted to Caucasian women, differences were no longer statistically significant. HM formate levels were also lower in atopic than non-atopic women ( $45 \%$ lower, $p=0.056)$ (Figure 1); this difference was statistically significant within Australian 
TABLE 1 | Characteristics of the cohort $(n=109)$.

\begin{tabular}{|c|c|c|c|c|c|}
\hline & $\begin{array}{c}\text { Australia } \\
(n=29)\end{array}$ & $\begin{array}{l}\text { Japan } \\
(n=12)\end{array}$ & $\begin{array}{l}\text { Norway } \\
(n=40)\end{array}$ & $\begin{array}{l}\text { South Africa } \\
\qquad(n=10)\end{array}$ & $\begin{array}{c}\text { USA } \\
(n=18)\end{array}$ \\
\hline Maternal atopy & $21(72 \%)$ & $6(50 \%)$ & $9(23 \%)$ & $0(0 \%)$ & $11(61 \%)$ \\
\hline Caucasian & $28(100 \%)$ & $0(0 \%)$ & $34(85 \%)$ & $2(20 \%)$ & $11(61 \%)$ \\
\hline Asian & $0(0 \%)$ & $12(100 \%)$ & $0(0 \%)$ & $0(0 \%)$ & $0(0 \%)$ \\
\hline Other race & $0(0 \%)$ & $0(0 \%)$ & $6(15 \%)$ & $0(0 \%)$ & $0(0 \%)$ \\
\hline Maternal age (years) & $33.8 \pm 5.2$ & $24.6 \pm 5.5$ & $29.4 \pm 5.2$ & $29.8 \pm 4.8$ & $29.6 \pm 4.4$ \\
\hline Maternal parity & $1.3 \pm 0.5$ & $1.7 \pm 1.0$ & $1.5 \pm 0.5$ & $2.0 \pm 0.9$ & $2.2 \pm 1.2$ \\
\hline Maternal pre-pregnancy BMI & & $20.7 \pm 2.5$ & $28.1 \pm 6.6$ & $25.0 \pm 2.9$ & $27.2 \pm 5.6$ \\
\hline Maternal antibiotics & $4(14 \%)^{\star}$ & $0(0 \%)$ & $5(13 \%)^{\wedge}$ & $0(0 \%)$ & $0(0 \%)$ \\
\hline
\end{tabular}

Values are reported as $n$ (percent) or mean $\pm S D$.

Blank cells represent missing data.

${ }^{*}$ One case of intrapartum Cefazolin for cesarean delivery, two cases of intrapartum penicillin for Group B Streptococcus, one case of intrapartum antibiotics with no class or reason recorded.

${ }^{\wedge}$ All exposures were in early pregnancy. Class of antibiotic was not recorded.

TABLE 2 | Levels of short chain fatty acids detected in 109 human milk samples taken at 1 month postpartum.

\begin{tabular}{lcccccc}
\hline & $\begin{array}{c}\text { Formate } \\
\text { (C1:0) }\end{array}$ & $\begin{array}{c}\text { Acetate } \\
\text { (C2:0) }\end{array}$ & $\begin{array}{c}\text { Propionate } \\
\text { (C3:0) }\end{array}$ & $\begin{array}{c}\text { Butyrate } \\
\text { (C4:0) }\end{array}$ & $\begin{array}{c}\text { Iso-butyrate } \\
\text { (C5:0) }\end{array}$ & $\begin{array}{c}\text { Valerate } \\
\text { (C5:0) }\end{array}$ \\
\hline Prevalence & $100 \%$ & $100 \%$ & $0 \%$ & $100 \%$ & $0 \%$ & $0 \%$ \\
Median & 43.7 & 46.8 & - & 95.6 & - & - \\
Minimum & 15.2 & 13.5 & - & 4.8 & - & - \\
Maximum & 4960.3 & 4307.7 & - & 409.5 & - & - \\
(C5:0)
\end{tabular}

Values are reported as \% prevalence or $\mu \mathrm{mol} / \mathrm{L}$.

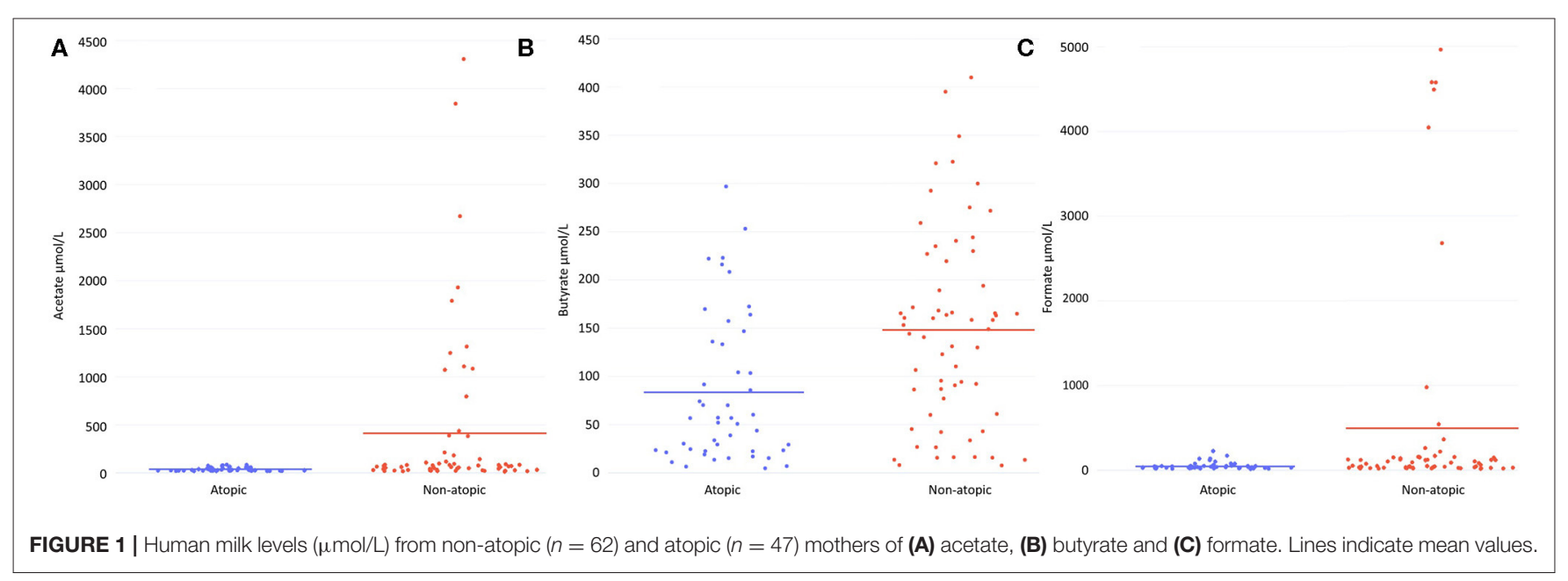

women $(p<0.0001)$ and within Norwegian women $(p=0.009)$. Overall, there were no differences in HM levels of the SCFA intermediates pyruvate, lactate, and succinate between atopic and non-atopic women (Supplementary Table 1). However, the $\mathrm{HM}$ of Australian women with atopy also had higher levels of lactate $(p=0.01)$ and pyruvate $(p<0.0001)$, and lower levels of succinate $(p=0.003)$ than of women without atopy.

Variations in HM SCFAs levels were also seen between women of the same atopic status living in different countries (Figure 2, Supplementary Table 2). As tested by mixed linear models, HM 


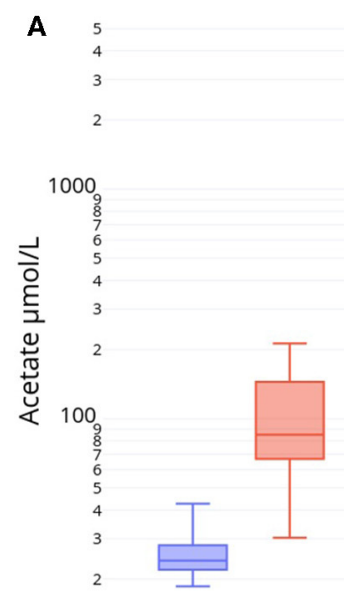

10

Australia

B

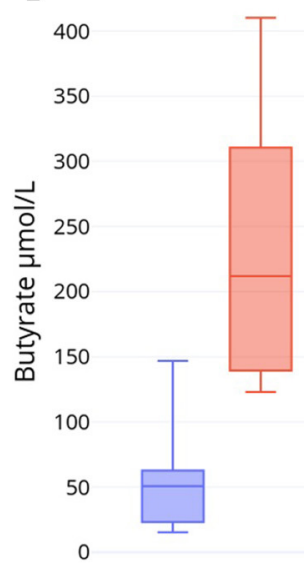

Australia

C
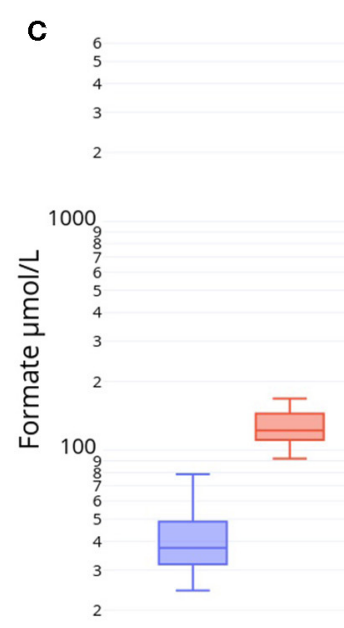

Australia
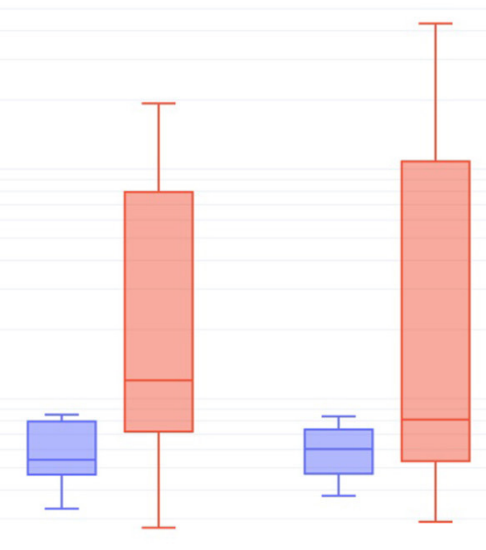

Japan

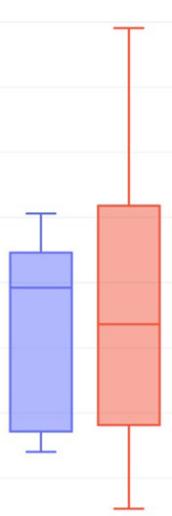

Japan

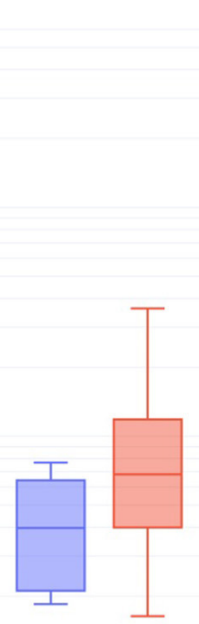

Japan

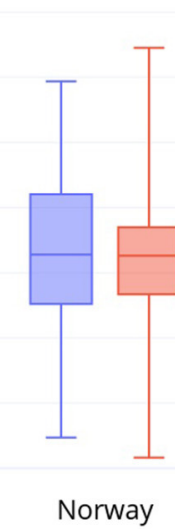

Norway

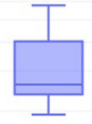

USA

$\square$ Atopic

$\square$ Non-atopic

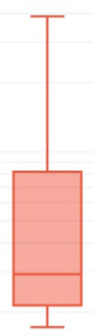

South Africa 
levels of butyrate were significantly lower in non-atopic US women compared to those living in Australia, Norway, or Japan ( $p=0.001, p=0.004$, and $p=0.02$, respectively) but not South Africa. HM butyrate levels were reduced in non-atopic South African women compared to non-atopic Australian women ( $p$ $=0.01)$. We conducted a sensitivity analysis that subdivided non-atopic women in the US by race into Black or Caucasian. Only among non-atopic Caucasian women from the US did butyrate levels remain significantly lower than among women in the above comparison.

Atopic women did not differ in their milk acetate or butyrate profiles if they lived in the US vs. Australia, or in Norway vs. Japan. HM from atopic Australian and US women had significantly lower levels of acetate and butyrate that that of atopic Norwegian and Japanese women $(p<0.001)$. HM from atopic Australian women also had lower levels of formate compared to that of US women $(p=0.02)$. No other differences in milk SCFA levels between countries were observed within either non-atopic or atopic women. In a sensitivity analysis that subdivided atopic women in the US by race, atopic Black or Caucasian women from the US continued to differ from Norwegian and Japanese atopic women in terms of lower acetate and butyrate levels in HM. Restricting the US-Australia comparison to atopic Caucasian women did not alter the lack of statistical difference for HM acetate or butyrate.

Levels of SCFA intermediate products also differed by country (Supplementary Table 2). Lactate levels were significantly higher in HM from non-atopic Japanese women compared to HM from other non-atopic women (Norway $p=0.003$, South Africa $p=$ 0.006 , Australia $p=0.008$, USA $p=0.01$ ). Similarly, lactate was elevated in HM from atopic Japanese mothers compared to atopic Norwegian mothers $(p=0.01)$. HM from non-atopic Japanese and South African mothers had significantly higher levels of pyruvate compared to non-atopic Australian and Norwegian mothers (Japan v. Australia $p=0.004$; Japan v. Norway $p=$ 0.008 ; South Africa v. Australia $p=0.02$; South Africa v. Norway $p=0.04)$. Finally, atopic Norwegian women had significantly higher levels of HM succinate compared to mothers from other countries $(p<0.001)$.

\section{DISCUSSION}

Here we report that HM contains detectable levels of SCFAs acetate, butyrate, and formate at 1 month postpartum. Collectively, HM levels of acetate and butyrate were significantly reduced in atopic women. This trend was retained for HM acetate in atopic women in Australia, Norway and Japan but not the US. Only among Australian women were HM formate and butyrate levels lower with atopic disease. SCFAs have been shown to be provide protection from allergy and atopy in mice, particularly through their effects on regulatory $\mathrm{T}$ cell and dendritic cell biology $(8,9,16)$. Higher relative levels of fecal acetate during pregnancy have been associated with reduced risk for hay fever, asthma and wheeze in the offspring of mothers with a history of atopy (15). In their study, fecal acetate levels were higher in mothers of breastfed infants. The ability of SCFAs to inhibit histone deacetylases suggests a role for HM-derived SCFAs in the epigenetic regulation of immune function and postnatal programming of atopy in breastfed offspring. Reduced levels of SCFAs in the HM of atopic women may therefore play a role in the intergenerational transmission of atopic disorders. Indeed, recent data demonstrate that low HM bacterial richness is associated with atopy development in early life (29). GomezGallergo et al. reported country differences in HM SCFA and their correlations with HM microbiota (26). We extend those findings by identifying maternal atopic status as a possible source of variation in HM SCFA.

The reduced levels of acetate in milk from atopic mothers may have other physiological consequences for breastfed infants. In cows, acetate is the major substrate of de novo fat synthesis in milk (30). It is unclear whether this is also true for humans (31), but HM acetate levels are found to be weakly correlated with HM fat concentrations (22). In general, breastfeeding is associated with reduced infant adiposity, and gut acetate levels are highest in exclusively breastfed infants $(32,33)$. SCFAs are involved in several biologic pathways that prevent overweight, including appetite suppression and promotion of fat oxidation over fat synthesis (7). Indeed, HM acetate levels are reported to be negatively associated with infant skinfold thickness (22). Maternal atopic status appears to over-ride the protective actions of prenatal anti-inflammatory cytokines against overweight development in offspring (34). Our study suggests that maternal atopic status may also reduce the availability of HM SCFAs to regulate fat metabolism in the breastfed infant. Acetate and butyrate are also involved in the production of long-chain fatty acids (31). However, contrary to our findings, HM long-chain fatty acid levels do not appear to differ by atopic status (35-37).

HM SCFA levels also varied between our cohorts. This is unsurprising given that the early life gut, adult gut, and HM microbiomes vary geographically $(38-41)$. These metabolites are also likely influenced by regional differences in diet that feed the gut microbiota toward enrichment with Bacteroidetes species in US/European populations. Since we did not collect maternal fecal or HM samples for bacterial profiling, we are unable to link alterations in HM SCFA profiles with specific members of the bacterial community. Gronlund et al. reported reduced bifidobacterial abundance in HM and in the gut microbiota of breastfed infants if mothers had atopic disease (42). Higher bifidobacterial abundance by 3 months of age, followed by an earlier switch to increasing abundance of butyrate-producing bacteria, has been found to be protective against later risk of atopy (43). Recently, Bifidobacterium, a key acetate-producing genus, was found to be less abundant in the stool of breastfed infants in the US vs. several African countries (41). Additionally, HM from mothers of US infants exhibited much lower overall bacterial diversity (41). While Bifidobacterium spp. chiefly produce acetate, they form symbiotic relationships with butyrateproducers such as Eubacterium (44). In HM, acetate and butyrate levels are positively correlated (22). It is thus interesting to note the exceptionally low levels of butyrate in HM from non-atopic US mothers of Caucasian ancestry.

Acetate, butyrate, and formate have been found in HM of women worldwide (20-26). The levels of SCFAs reported here 
are in line with those recently reported by Prentice et al. as determined by NMR and GC-MS (at 1-2 months postpartum), and by $\mathrm{Wu}$ et al. (across lactation) and Smilowitz et al. (at 3 months) by NMR (20-22). We also confirm the positive correlations of HM acetate with butyrate and formate reported by Prentice et al. The failure by us and others to detect propionate in HM is curious. Presumably, SCFAs, which are produced in the gut, enter HM from the maternal circulation. Thornburn et al. reported that the three most abundantly produced SCFAs in humans (acetate, butyrate, and propionate) were approximately equal in concentration in the sera of pregnant women (median levels $51.4 \mu \mathrm{mol} / \mathrm{L}$ for acetate, $37.1 \mu \mathrm{mol} / \mathrm{L}$ for propionate, and $35.6 \mu \mathrm{mol} / \mathrm{L}$ for butyrate) (8). SCFAs present in HM may be produced by the resident HM microbiota; however, evidence for this possibility is currently lacking. Regardless, the presence of SCFAs in HM likely has important consequences for the developing infant. Endogenous production of SCFAs is low in early infancy (45). Maternally provided SCFAs may, therefore, supplement breastfed infants during the early periods of gut microbiome immaturity.

A major strength of our study is the use of multiple cohorts from around the world. However, this also means that samples were not uniformly collected and stored. Lack of standardized collection by time of day is not an issue for our comparison since there is no evidence for diurnal variation in HM SCFAs (21). On the other hand, some SCFAs are sensitive to storage temperatures higher than $-80^{\circ} \mathrm{C}$, the temperature at which SCFAs are highly stable for up to 2 months (46). Slight increases to levels of HM butyrate $(4 \mu \mathrm{mol} / \mathrm{L})$ are initially seen after short periods of storage at $-20^{\circ} \mathrm{C}$ compared to storage at $-80^{\circ} \mathrm{C}$ (21), followed by modest declines in butyrate with longer $\mathrm{HM}$ storage times at $-20^{\circ} \mathrm{C}$ for up to 16 years (22). Unfortunately, no studies have compared long term storage at $-20^{\circ} \mathrm{C}$ to $-80^{\circ} \mathrm{C}$. While variation in storage conditions may be an unavoidable limitation of our study, it is unlikely to explain the much lower levels of HM butyrate observed in the Australian atopic samples (stored at $-80^{\circ} \mathrm{C}$ ) or to explain within country differences or between country similarities. More importantly, the very large difference in milk butyrate between our Australian cohorts (161 $\mu \mathrm{mol} / \mathrm{L}$ lower levels in atopic women) is in the opposite direction to the above stability findings since atopic samples were stored immediately at $-80^{\circ} \mathrm{C}$, whereas the more recently-collected non-atopic samples were stored at $-20^{\circ} \mathrm{C}$. Our non-standard definition of "atopy" across cohorts is also a major limitation of this comparison, although similar trends were observed for HM from Norway and Japan despite the absence of serum IgE testing in Norwegian women. Other limitations include not having samples from atopic women from South Africa, and lacking balance in atopy status and number of participants per country. Finally, data were not available for all cohorts on maternal parity, body-mass index or socioeconomic status, but these characteristics have not been found to be correlated with HM SCFA levels (22). On the other hand, this study would have benefited from information on maternal diet, which may have strengthened similar findings by atopic status in two countries with high fermented food intake-Norway and Japan.

\section{CONCLUSION}

Our findings suggest that HM SCFA levels may vary by maternal atopic status and country of residence, a finding that could not be attributed to race. Despite sharing Caucasian ancestry, HM SCFA profiles for atopic women differed in Norway vs. the US or Australia. On the other hand, similar HM SCFA profiles by atopic status were seen in Norway and Japan. Lower levels of HM SCFAs have the potential to alter immune programming and fat metabolism in the breastfed offspring of women. This has implications for non-atopic women as well. In our study, this singled out women in the US who had the lowest levels of HM acetate and butyrate compared to non-atopic women in other countries.

\section{DATA AVAILABILITY STATEMENT}

The datasets generated for this study are available on request to the corresponding author.

\section{ETHICS STATEMENT}

The studies involving human participants were reviewed and approved by Human Research Ethics Committee of The University of Western Australia, Human Research Ethics Committee of the Princess Margaret Hospital, Committee on Human Research of Chiba University, Institutional Review Board at Henry Ford Health System, Norwegian Regional Committees for Medical and Health Research Ethics, and University of Cape Town Human Research Ethical Committee. The patients/participants provided their written informed consent to participate in this study.

\section{AUTHOR CONTRIBUTIONS}

PK performed the NMR analysis. LS drafted the manuscript and contributed to data analysis and visualization. MG contributed to data analysis and visualization. ET, ME, CJ, GW, NS, DC, SP, DM, DG, and AK oversaw recruitment, sample collection, storage, and funding for their respective cohorts. All authors reviewed and critically edited the manuscript.

\section{FUNDING}

This research was funded by the World Universities Network (WUN) and Canadian Institutes of Health Research (CIHR). DG, LS, and MG received an unrestricted research grant from Medela A.G, administered through the University of Western Australia. Medela A.G had no involvement in any aspect of the study design, analysis, or interpretation.

\section{ACKNOWLEDGMENTS}

We are grateful to the mothers who provided their valuable data in the individual study cohorts and the research assistants who collected it. We wish to acknowledge Khanh $\mathrm{Vu}$ for assisting in the statistical analysis for this manuscript. We 
also acknowledge the inVIVO LactoActive study investigators: AK (lead), University of Alberta; DC, Children's Hospital at Westmead \& University of Sydney; Cecilie Dahl, Norwegian Institute of Public Health; ET, University of Cape Town; ME, Norwegian Institute of Public Health; MG, University of Western Australia; DG, University of Western Australia; Aveni Haynes, University of Western Australia; Peter Hsu, Children's Hospital at Westmead \& University of Sydney; PK, University of Alberta; CJ, Henry Ford Hospital; Charles Mackay, Monash University; DM, Imperial College London \& Sechenov University; John Penders, Maastricht University; Harald Renz, University of Marburg; SP, Perth Children's Hospital \& University of Western Australia; NS, Chiba University; Carolyn M. Slupsky, University of California Davis; Carel Thijs, Maastricht University; GW, Henry Ford Hospital; Christina West, Umea University.

\section{REFERENCES}

1. Horta BL, Bahl R, Martinés JC, Victora CG, World Health O. Evidence on the Long-term Effects of Breastfeeding: Systematic Review and Meta-analyses. Geneva: World Health Organization (2007).

2. Lodge CJ, Tan DJ, Lau MX, Dai X, Tham R, Lowe AJ, et al. Breastfeeding and asthma and allergies: a systematic review and meta-analysis. Acta Paediatr. (2015) 104:38-53. doi: 10.1111/apa.13132

3. Arshad SH, Karmaus W, Zhang H, Holloway JW. Multigenerational cohorts in patients with asthma and allergy. J Allergy Clin Immunol. (2017) 139:41521. doi: 10.1016/j.jaci.2016.12.002

4. Morkve Knudsen T, Rezwan FI, Jiang Y, Karmaus W, Svanes C, Holloway JW. Transgenerational and intergenerational epigenetic inheritance in allergic diseases. J Allergy Clin Immunol. (2018) 142:765-72. doi: 10.1016/j.jaci.2018.07.007

5. Gay MCL, Koleva PT, Slupsky CM, Toit ED, Eggesbo M, Johnson CC, et al. Worldwide variation in human milk metabolome: indicators of breast physiology and maternal lifestyle? Nutrients. (2018) 10:1151. doi: 10.3390/nu10091151

6. Isganaitis E, Venditti S, Matthews TJ, Lerin C, Demerath EW, Fields DA. Maternal obesity and the human milk metabolome: associations with infant body composition and postnatal weight gain. Am J Clin Nutr. (2019) 110:11120. doi: $10.1093 /$ ajen/nqy334

7. Kumari M, Kozyrskyj AL. Gut microbial metabolism defines host metabolism: an emerging perspective in obesity and allergic inflammation. Obes Rev. (2017) 18:18-31. doi: 10.1111/obr.12484

8. Thorburn AN, McKenzie CI, Shen S, Stanley D, Macia L, Mason LJ, et al. Evidence that asthma is a developmental origin disease influenced by maternal diet and bacterial metabolites. Nat Commun. (2015) 6:7320. doi: $10.1038 /$ ncomms 8320

9. Trompette A, Gollwitzer ES, Yadava K, Sichelstiel AK, Sprenger N, Ngom-Bru $\mathrm{C}$, et al. Gut microbiota metabolism of dietary fiber influences allergic airway disease and hematopoiesis. Nat Med. (2014) 20:159-66. doi: 10.1038/nm.3444

10. Furusawa Y, Obata Y, Fukuda S, Endo TA, Nakato G, Takahashi D, et al. Commensal microbe-derived butyrate induces the differentiation of colonic regulatory T cells. Nature. (2013) 504:446-50. doi: 10.1038/nature12721

11. Hogenkamp A, Knippels LM, Garssen J, van Esch BC. Supplementation of mice with specific nondigestible oligosaccharides during pregnancy or lactation leads to diminished sensitization and allergy in the female offspring. J Nutr. (2015) 145:996-1002. doi: 10.3945/jn.115.210401

12. Hogenkamp A, Thijssen S, van Vlies N, Garssen J. Supplementing pregnant mice with a specific mixture of nondigestible oligosaccharides reduces symptoms of allergic asthma in male offspring. J Nutr. (2015) 145:640-6. doi: $10.3945 /$ jn. 114.197707

13. Registry ANZCT. A Randomised, Double-blind, Placebo-Controlled Trial to Investigate the Effects of Maternal Dietary Prebiotic Fibre Supplementation, From Early Pregnancy to 6 Months Lactation, on Infant Outcomes of Immune

\section{SUPPLEMENTARY MATERIAL}

The Supplementary Material for this article can be found online at: https://www.frontiersin.org/articles/10.3389/fimmu. 2020.01427/full\#supplementary-material

Supplementary Figure 1 | Partial Least Square Discriminant Analysis (PLS-DA) loading plot (Left) and scatterplot (Right) of human milk metabolites from 109 women in various countries. The score plot shows separation based on maternal atopic status. The loading plot shows the milk metabolites that influence the separation based on maternal atopic status.

Supplementary Table 1 | Levels of short chain fatty acid intermediates detected in human milk samples from atopic $(n=47)$ and non-atopic $(n=62)$ women at one month postpartum. Values are reported as $\%$ prevalence or $\mu \mathrm{mol} / \mathrm{L}$.

Supplementary Table 2 | Mean levels of short chain fatty acid and intermediates detected in human milk samples from atopic and non-atopic women at one month postpartum in five international cohorts. Values are reported as $\mu \mathrm{mol} / \mathrm{L}$.

Function and Eczema Diagnosis. Sydney: University of Sydney: NHMRC Clinical Trials Centre (2015).

14. Cabridain C, Aubert H, Kaeffer B, Badon V, Boivin M, Dochez V, et al. Effectiveness of an antenatal maternal supplementation with prebiotics for preventing atopic dermatitis in high-risk children (the PREGRALL study): protocol for a randomised controlled trial. BMJ Open. (2019) 9:e024974. doi: 10.1136/bmjopen-2018-024974

15. Lee-Sarwar KA, Kelly RS, Lasky-Su J, Zeiger RS, O'Connor GT, Sandel MT, et al. Fecal short-chain fatty acids in pregnancy and offspring asthma and allergic outcomes. J Allergy Clin Immunol Pract. (2019) 8:1100-2.

16. Tan J, McKenzie C, Vuillermin PJ, Goverse G, Vinuesa CG, Mebius RE, et al. Dietary fiber and bacterial SCFA enhance oral tolerance and protect against food allergy through diverse cellular pathways. Cell Rep. (2016) 15:2809-24. doi: 10.1016/j.celrep.2016.05.047

17. Tan J, McKenzie C, Potamitis M, Thorburn AN, Mackay CR, Macia L. The role of short-chain fatty acids in health and disease. Adv Immunol. (2014) 121:91-119. doi: 10.1016/B978-0-12-800100-4.00003-9

18. Thorburn AN, Macia L, Mackay CR. Diet, metabolites, and "westernlifestyle" inflammatory diseases. Immunity. (2014) 40:833-42. doi: 10.1016/j.immuni.2014.05.014

19. Boix-Amoros A, Collado MC, Van't Land B, Calvert A, Le Doare K, Garssen J, et al. Reviewing the evidence on breast milk composition and immunological outcomes. Nutr Rev. (2019) 77:nuz019. doi: 10.1093/nutrit/nuz019

20. Smilowitz JT, O'Sullivan A, Barile D, German JB, Lonnerdal B, Slupsky CM. The human milk metabolome reveals diverse oligosaccharide profiles. J Nutr. (2013) 143:1709-18. doi: 10.3945/jn.113.178772

21. Wu J, Domellof M, Zivkovic AM, Larsson G, Ohman A, Nording ML. NMRbased metabolite profiling of human milk: a pilot study of methods for investigating compositional changes during lactation. Biochem Biophys Res Commun. (2016) 469:626-32. doi: 10.1016/j.bbrc.2015.11.114

22. Prentice PM, Schoemaker MH, Vervoort J, Hettinga K, Lambers TT, van Tol EAF, et al. Human milk short-chain fatty acid composition is associated with adiposity outcomes in infants. J Nutr. (2019) 149:716-22. doi: 10.1093/jn/nxy320

23. Precht D, Molkentin J. C18:1, C18:2 and C18:3 trans and cis fatty acid isomers including conjugated cis delta 9 , trans delta 11 linoleic acid (CLA) as well as total fat composition of German human milk lipids. Nahrung. (1999) 43:233-44. doi: 10.1002/(SICI) 1521-3803(19990801)43:4<233::AIDFOOD233>3.0.CO;2-B

24. Santillo A, Figliola L, Ciliberti MG, Caroprese M, Marino R, Albenzio M. Focusing on fatty acid profile in milk from different species after in vitro digestion. J Dairy Res. (2018) 85:257-62. doi: 10.1017/S00220299180 00274

25. Meng X, Dunsmore G, Koleva P, Elloumi Y, Wu RY, Sutton RT, et al. The profile of human milk metabolome, cytokines, and antibodies in inflammatory bowel diseases versus healthy mothers, and potential impact on the newborn. J Crohns Colitis. (2019) 13:431-41. doi: 10.1093/ecco-jcc/jjy186 
26. Gomez-Gallego C, Morales JM, Monleon D, du Toit E, Kumar H, Linderborg $\mathrm{KM}$, et al. Human breast milk NMR metabolomic profile across specific geographical locations and its association with the milk microbiota. Nutrients. (2018) 10:1355. doi: 10.3390/nu10101355

27. Jost T, Lacroix C, Braegger C, Chassard C. Stability of the maternal gut microbiota during late pregnancy and early lactation. Curr Microbiol. (2014) 68:419-27. doi: 10.1007/s00284-013-0491-6

28. Demmelmair H, Koletzko B. Variation of metabolite and hormone contents in human milk. Clin Perinatol. (2017) 44:151-64. doi: 10.1016/j.clp.2016.11.007

29. Dzidic M, Mira A, Artacho A, Abrahamsson TR, Jenmalm MC, Collado CM. Allergy development is associated with consumption of breastmilk with a reduced microbial richness in the first month of life. Pediatr Allergy Immunol. (2019) 31:250-7. doi: 10.1111/pai.13176

30. Urrutia NL, Harvatine KJ. Acetate dose-dependently stimulates milk fat synthesis in lactating dairy cows. J Nutr. (2017) 147:763-9. doi: 10.3945 /jn.116.245001

31. Jenness R. Proceedings: biosynthesis and composition of milk. J Invest Dermatol. (1974) 63:109-18. doi: 10.1111/1523-1747.ep12678111

32. Victora CG, Bahl R, Barros AJ, Franca GV, Horton S, Krasevec J, et al. Breastfeeding in the 21st century: epidemiology, mechanisms, and lifelong effect. Lancet. (2016) 387:475-90. doi: 10.1016/S0140-6736(15)01024-7

33. Bridgman SL, Azad MB, Field CJ, Haqq AM, Becker AB, Mandhane PJ, et al. Fecal short-chain fatty acid variations by breastfeeding status in infants at 4 months: differences in relative versus absolute concentrations. Front Nutr. (2017) 4:11. doi: 10.3389/fnut.2017.00011

34. Englich B, Herberth G, Rolle-Kampczyk U, Trump S, Roder S, Borte M, et al. Maternal cytokine status may prime the metabolic profile and increase risk of obesity in children. Int J Obes. (2017) 41:1440-6. doi: 10.1038/ijo.2017.113

35. Thijs C, Muller A, Rist L, Kummeling I, Snijders BE, Huber M, et al. Fatty acids in breast milk and development of atopic eczema and allergic sensitisation in infancy. Allergy. (2011) 66:58-67. doi: 10.1111/j.1398-9995.2010.02445.x

36. Hua MC, Su HM, Kuo ML, Chen CC, Yao TC, Tsai MH, et al. Association of maternal allergy with human milk soluble CD14 and fatty acids, and early childhood atopic dermatitis. Pediatr Allergy Immunol. (2019) 30:204-13. doi: 10.1111/pai.13011

37. Miliku K, Duan QL, Moraes TJ, Becker AB, Mandhane PJ, Turvey SE, et al. Human milk fatty acid composition is associated with dietary, genetic, sociodemographic, and environmental factors in the CHILD cohort Study. Am J Clin Nutr. (2019) 110:1370-83. doi: 10.1093/ajcn/nqz229

38. Fallani M, Young D, Scott J, Norin E, Amarri S, Adam R, et al. Intestinal microbiota of 6-week-old infants across Europe: geographic influence beyond delivery mode, breast-feeding, and antibiotics. J Pediatr Gastroenterol Nutr. (2010) 51:77-84. doi: 10.1097/MPG.0b013e3181d1b11e
39. Yatsunenko T, Rey FE, Manary MJ, Trehan I, Dominguez-Bello MG, Contreras $\mathrm{M}$, et al. Human gut microbiome viewed across age and geography. Nature. (2012) 486:222-7. doi: 10.1038/nature11053

40. Gupta VK, Paul S, Dutta C. Geography, ethnicity or subsistence-specific variations in human microbiome composition and diversity. Front Microbiol. (2017) 8:1162. doi: 10.3389/fmicb.2017.01162

41. Lackey KA, Williams JE, Meehan CL, Zachek JA, Benda ED, Price WJ, et al. What's normal? Microbiomes in human milk and infant feces are related to each other but vary geographically: the INSPIRE study. Front Nutr. (2019) 6:45. doi: 10.3389/fnut.2019.00045

42. Gronlund MM, Gueimonde M, Laitinen K, Kociubinski G, Gronroos T, Salminen S, et al. Maternal breast-milk and intestinal bifidobacteria guide the compositional development of the Bifidobacterium microbiota in infants at risk of allergic disease. Clin Exp Allergy. (2007) 37:1764-72. doi: 10.1111/j.1365-2222.2007.02849.x

43. Ruohtula T, de Goffau MC, Nieminen JK, Honkanen J, Siljander H, Hamalainen AM, et al. Maturation of gut microbiota and circulating regulatory $\mathrm{T}$ cells and development of IgE sensitization in early life. Front Immunol. (2019) 10:2494. doi: 10.3389/fimmu.2019.02494

44. Bunesova V, Lacroix C, Schwab C. Mucin cross-feeding of infant Bifidobacteria and Eubacterium hallii. Microb Ecol. (2018) 75:228-38. doi: 10.1007/s00248-017-1037-4

45. Verbeke KA, Boobis AR, Chiodini A, Edwards CA, Franck A, Kleerebezem $\mathrm{M}$, et al. Towards microbial fermentation metabolites as markers for health benefits of prebiotics. Nutr Res Rev. (2015) 28:42-66. doi: 10.1017/S0954422415000037

46. Ueyama J, Oda M, Hirayama M, Sugitate K, Sakui N, Hamada R, et al. Freeze-drying enables homogeneous and stable sample preparation for determination of fecal short-chain fatty acids. Anal Biochem. (2020) 589:113508. doi: 10.1016/j.ab.2019.113508

Conflict of Interest: All authors declare that the research was conducted in the absence of any commercial or financial relationships that could be construed as a potential conflict of interest.

Copyright (c) 2020 Stinson, Gay, Koleva, Eggesbø, Johnson, Wegienka, du Toit, Shimojo, Munblit, Campbell, Prescott, Geddes and Kozyrskyj. This is an open-access article distributed under the terms of the Creative Commons Attribution License (CC $B Y)$. The use, distribution or reproduction in other forums is permitted, provided the original author(s) and the copyright owner(s) are credited and that the original publication in this journal is cited, in accordance with accepted academic practice. No use, distribution or reproduction is permitted which does not comply with these terms. 